\title{
PROPELLER LOAD MODELLING IN THE CALCULATIONS OF MARINE SHAFTING TORSIONAL VIBRATIONS
}

\author{
Nenad Vulić, Karlo Bratić, Branko Lalić, Ladislav Stazić \\ University of Split (Croatia)
}

\begin{abstract}
Technical rules of IACS classification societies require that calculations of torsional vibrations for all propulsion shafting systems, as well as for shafting systems of auxiliary machinery above certain power, shall be prepared, submitted and validated for the vessels requesting the class certificate. These calculations may be approached either by conventional analytical models based upon systems of ordinary differential equations describing the actual dynamic system, or by simulation modelling of the same dynamic system. The research team of the authors has been established within the R\&D Centre of the Faculty of Maritime Studies at Split. The aim of the team is to investigate possibilities and constraints for implementation of the SimulationX software to the simulation modelling of torsional vibrations of dynamic systems, such as marine propulsion and auxiliary shafting. In general, results of these calculations depend upon the concept of the system (two-stroke vs. four-stroke Diesel engine, torsional vibration damper present or not, flexible coupling present or not, fixed pitch or controllable pitch propeller, etc.), dimensions of components, their material properties and service loading. Propeller load modelling within the service loading is very important. Even the preliminary research results show that its simplest part, i.e. the steady-state propeller loading of the system without taking excitations into account, may have a significant influence on the results of torsional vibrations calculation and consequently even to their acceptability by the class society. For this reason, the present paper describes two different ways to express propeller steadystate loading formulations, as prescribed by different sources and authorities, as well as their influence on the torsional vibrations calculation results and meeting the criteria of the IACS Unified Requirements, presenting them in a real verified and validated case study.

Keywords: propeller curve; simulation modelling; propulsion system; steadystate dynamic response
\end{abstract}

\section{Introduction}

The International Association of Classification Societies (IACS) requires that the Rules for the Classification of Ships, developed by its member organizations, as 
the fundamental basis for assigning the IACS society class to a ship, comprise all the Unified Requirements (URs) that have been prepared by the IACS Panels, accepted by the IACS General Policy Group (GPG) and adopted by the IACS Council'). One of these URs, that defines criteria for the acceptability of dynamic response of the main propulsion shafting system, expressed in the allowable amplitudes of tangential stresses in shafting sections due to the steady state excitations caused by torsional vibrations is IACS UR M682).

In general, according to the classification rules of the IACS member societies, calculations of torsional vibrations shall be performed for main propulsion systems of all the ships with the gross tonnage GT 100 and above requesting the class certificate, as well as auxiliary shafting systems of these ships over certain power as defined in these Rules. IACS societies require that designers prepare torsional vibration analysis calculations, then their verification within the appraisal process by the class society experts and finally the validation of the results by measurements on board performed by approved service suppliers.

These are rather strict requirements. Many software programs for these calculations have successfully been developed over many years. Many highly competent testing institutions around the world have been approved as the service suppliers for these measurements. Regardless of all of this, problems with the failures caused by torsional vibrations still occur in practice, showing that this phenomenon still deserves due attention. This is one of the reasons why the research team of the authors of this paper has been established within the R\&D Centre of the Faculty of Maritime Studies at Split. The aim of the team is to investigate the possibilities and constraints for implementation of simulation modelling software to the calculation of torsional vibrations of dynamic systems such as marine propulsion and auxiliary shafting.

The steady-state response of the main propulsion shafting depends upon the conceptual layout of the system, dimensions of the components, their material properties and loading of the system. This loading comprises steadystate propeller loads, gas forces and inertia forces in engine cylinders as well as propeller excitation.

The aim of this paper is to present the different possible approaches to model the steady-state propeller load and its influence to the results of the calculations of torsional vibrations as obtained by the simulation modelling software such as SimulationX, as well as to present this influence on a selected verified and validated case study.

Propeller curve for various types of propellers and determination of the propeller design point on the basis of the intersection of this curve with the engine characteristics curve have been described in (Carlton 2019) with all the details. Analytical approach to torsional vibrations calculations has been described in VDI guideline ${ }^{3)}$, as well as in the recent publications (Senjanović 2019, $227-244$; 
Senjanović 2019, 107 - 120). Some specific details regarding simulation modelling approach in torsional vibrations calculations have been presented in the previous publications of the authors, i.e. (Vulić et al. 2016; Vulić et al. 2017). However, neither of these relatively recent publications analyzes the influence of the implemented formulation of the propeller curve to the results of shafting torsional vibrations steady state responses, thus justifying the research topic of the present paper.

\section{Problem formulation}

Understanding the propeller as the component of the marine propulsion system with the task to convert the torque received through the propeller shaft into thrust force to be transmitted to the ship hull, it is easy to conclude that the value of this torque is essential for the static and dynamic behavior of the propulsion system. This torque is generated by the prime mover, such as marine Diesel engine and is expressed in terms of engine power at a certain speed, e.g. maximal continuous rated power (MCR) at nominal speed. The propeller determines the amount of torque that it takes from the propulsion system to produce thrust, whereas the prime mover shall be capable to generate enough power to produce this torque, dependent upon the actual operating conditions. This is especially important to be understood for the steady-state propulsion system operation, at its constant speed of rotation, when the torque absorbed by the propeller is in balance with the torque originating from the prime mover, if the power losses in gearboxes and bearings are neglected. This means that the relationship between the propeller torque and the prime mover nominal torque for any speed within the operating speed range is very important and shall be described analytically.

Steady-state propeller torque $M_{t}$ at the operating speed $n$ may be expressed in terms of nominal prime mover torque $M_{0}$, i.e. the one at engine nominal speed by means of the following formula ${ }^{4}$ :

$$
M_{t}=M_{\text {tMCR }}\left(\frac{n}{n_{M C R}}\right)^{2}
$$

where:

$M_{t M C R}$ - prime mover torque produced at MCR power, $\mathrm{Nm}$

$n_{M C R}$ - nominal engine speed at MCR power, rpm

If the torque is expressed in terms of engine power by means of the following basic well-known unit dependent formula (valid also for the MCR power):

$$
M_{t}=\frac{30 \cdot 10^{3}}{\pi} \frac{P}{n}
$$

then the so-called propeller curve $P(n)$ will be obtained by the following formula ${ }^{4)}$ : 
$P=P_{M C R}\left(\frac{n}{n_{M C R}}\right)^{3}$

where:

$P$-actual power absorbed by the propeller, $\mathrm{kW}$

$n-$ actual steady-state speed, rpm

$P_{M C R}-\mathrm{MCR}$ power, $\mathrm{kW}$

$n_{M C R}-$ nominal speed at MCR power, rpm

\section{Methods}

The propeller curve, as expressed by the formula (3), either in its linear or logarithmic form is widely and extensively used in practice, e.g. to determine the limit engine speed if the engine power is to be limited for several possible reasons.

However, at a second thought and a deeper insight, the propeller curve (3) has one easy-to-be-noticed disadvantage. Mean indicated pressures in engine cylinders may be expressed in terms of speed in the same way as the torques in formula (1). In any case when the prime mover starts running, it has to bring the propulsion system to its certain actual speed starting from its zero speed. There exists the lowest speed of the stabile operation of the prime mover, which is tested during Diesel engines type tests. Considering the behavior of the propulsion system at very low speeds below this minimal stabile speed and the fact that it has to start its operation from the zero speed, it is obvious that at these very low speeds friction forces, originating from the friction in the sliding and reciprocating engine components (e.g. piston rings against engine cylinders, cross head against cross head sliding bearings, etc.) are dominating over other influences. They are also practically constant at these very low speeds.

The influence of these friction forces may be understood as the quantity dependent upon the difference between the mean indicated pressure in engine cylinders and the mean effective pressure. For the explained reason the formula (3) is to be modified somehow in order to introduce this influence of frictional forces in a form of a constant term at low speeds.

Engine manufacturers have faced this problem rather long ago and propose a different expression for the power-speed relation compared to formula (3).

In their publication ${ }^{5)}$, MAN Energy Solutions (formerly MAN B\&W Diesel A/S) provides a different formula from which it follows that generally $96 \%$ of engine indicated power is transmitted to the propeller, where the remaining $4 \%$ is spent to overcome the previously described frictional influences. Consequentially, in accordance with ${ }^{5}$ the following formula is to be applied, expressing loads in terms of mean pressures: 
$p_{m, i}=\left[0,96 \cdot\left(\frac{n}{n_{M C R}}\right)^{2}+0,04\right] \cdot p_{m, e M C R}+p_{D}$

where:

$p_{m, i}$ - mean indicated pressure at speed $n$

$p_{m, e M C R}-$ mean effective pressure at MCR

$p_{D}$ - drag pressure

$$
p_{D}=p_{m, i M C R}-p_{m, e M C R}
$$

$p_{m, i M C R}-$ mean indicated pressure at MCR

Mechanical efficiency ratio is defined as follows:

$$
\eta_{m}=\frac{p_{m, e M C R}}{p_{m, i M C R}}
$$

Substituting formula (6) and (5) into (4), it follows:

$$
p_{m, i}=\left[0,96 \eta_{m} \cdot\left(\frac{n}{n_{M C R}}\right)^{2}+\left(1-\eta_{m}\right)\right] \cdot p_{m, i M C R}
$$

or in terms of torque vs. mean indicated pressure:

$$
M_{t}=\frac{1}{\eta_{m}}\left[\frac{p_{m, i}}{p_{m, i M C R}}-\left(1-\eta_{m}\right)\right] \cdot M_{t, M C R}
$$

where:

$M_{t}-$ torque at speed $n$, referent to $p_{m, i}$

$M_{t, M C R}^{t}-$ torque at MCR

Formulas (4) and (8) as presented above are practically equivalent to each other. The selection of either of them depends just upon the fact whether the torsional vibrations analysis software uses the steady-state propeller loading based upon mean indicated pressures, as in formula (4) or the torque vs. speed, as in formula (8), where the speed is again entered into (4) to obtain the mean effective pressure at that speed.

\section{Solutions}

The basic idea to find out if the method of modelling of the steady-state propeller load has an influence on the results of calculations of torsional vibrations is to compare the results of calculations for the propeller load based upon the conventional propeller curve, formula (1) or (3), with the ones obtained by means of the formulas (4) or (8), taking frictional forces and mechanical efficiency ratio into account.

The calculations are performed by means of the torsional vibrations analysis module (TVA) of the SimulationX software. SimulationX is the very extensive 
and powerful software package based upon simulation modelling approach and elements developed in Modellica language platform. The use of SimulationX becomes more and more popular, especially within IACS classification societies, though it requires specialist knowledge and expertise in order to prepare data and interpret the final results. SimulationX fits this purpose properly, because it deals with the linear and non-linear elements in the model equally, without any particular problems.

It is the basic aim of this paper only to shed some more light on the selection of the proper formulation of the loading in the SimulationX element for modeling propeller, whether this will produce different output results and to what extent.

SimulationX allows several models to be used for the modelling of the excitations within the engine cylinders due to gas forces. These can be used in the same cylinder model, by just selecting of either cylinder pressure model or crank torque model before initiating the calculation.

Cylinder pressure model takes into account the pressure vs. crank angle in each of the cylinders. This curve may be obtained by its recording on a cylinder of the actual engine type in question, or is provided by the engine licensor within the process of the engine type approval.

Crank torque model input data consist of the external torque acting on the crankshaft journal vs. crank angle for each of the engine cylinders. When needed, the torques acting on crank may be determined from the cylinder pressures by the procedure presented in (Vulić et al. 2007).

Though the final excitation values for the cylinder pressure and crank torque model are expected to be equal when expressed in comparable terms and to produce identical results, it is not the case in simulation modeling approach and SimulationX. Consequentially, both excitation models are to be evaluated and taken to be compared.

\section{Results and discussion}

Methods and solutions described in the two previous sections will be presented in the case study example of the propulsion shafting system torsional vibrations analysis calculations for the ship built long ago at a Croatian shipyard and still in operation without any problems regarding her main propulsion shafting.

The case study ship in question is the 27539 GT oil/chemical tanker with the carrying capacity of 44781 tons. The ship overall length is $183,4 \mathrm{~m}$, her maximal breadth is $32,3 \mathrm{~m}$ and her design draught $11,0 \mathrm{~m}$.

The ship propulsion system consists of one two-stroke six-cylinders slow-speed single acting marine diesel engine, with the MCR power of $9180 \mathrm{~kW}$ at $123 \mathrm{rpm}$, one carbon steel intermediate shaft of $420 \mathrm{~mm}$ in diameter, one carbon steel propeller shaft of $465 \mathrm{~mm}$ in diameter and one four bladed bronze propeller. There are no reduction gearboxes or torsional vibration dampers within this propulsion system. 
Figure 1 presents the scheme with all of the input data necessary for the torsional vibrations analysis.

Figure 2 shows the actual torsional vibration analysis model with its elements as prepared and implemented in SimulationX.

It is also important to select the proper value for the comparison of the results of free and forced vibrations.

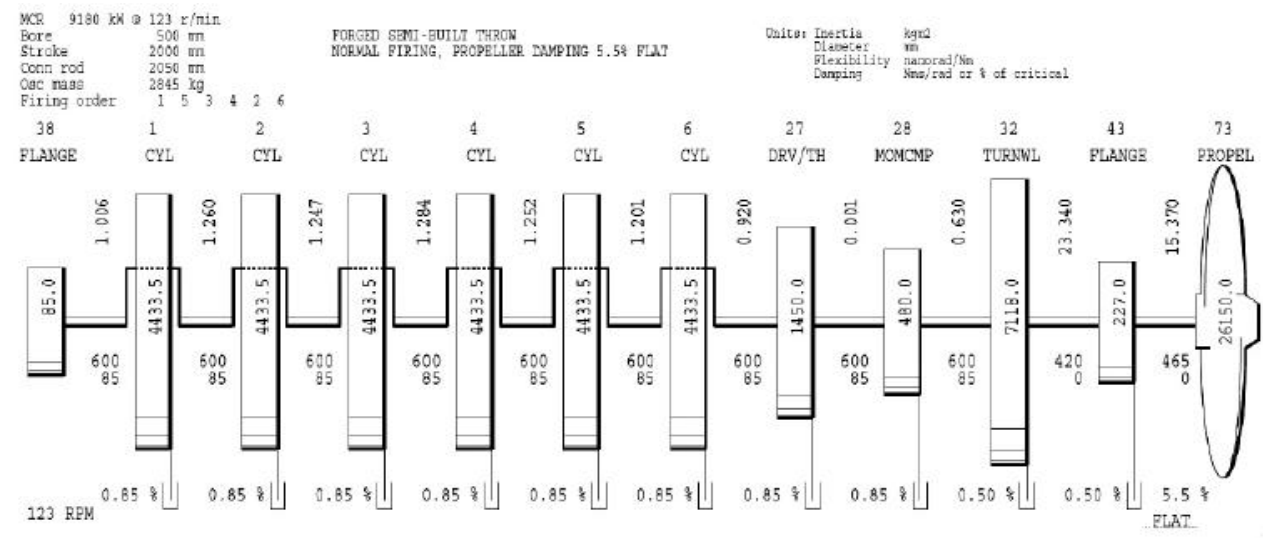

Figure 1. Scheme with the case-study torsional vibration analysis input data

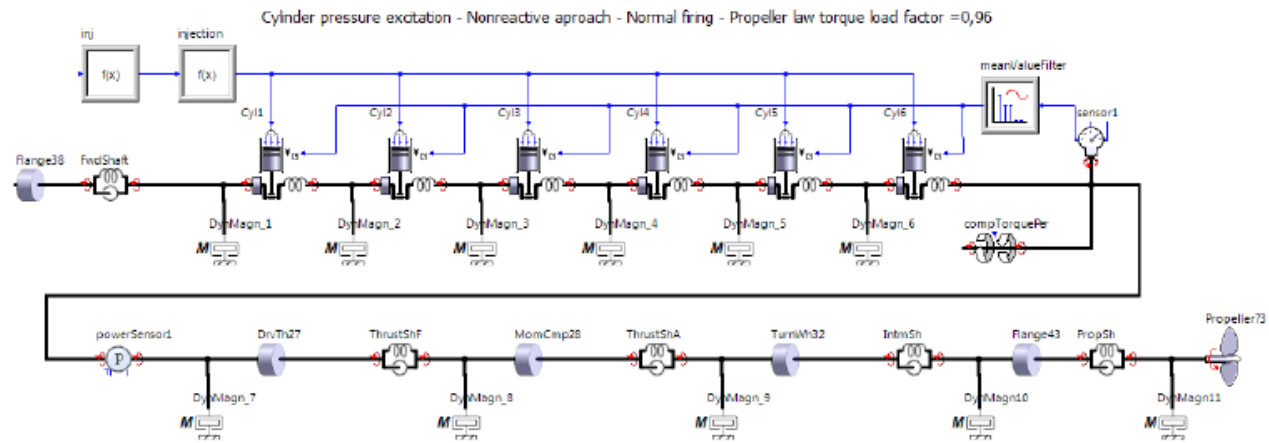

Figure 2. SimulationX model for the torsional vibration analysis data

This means that the proper information to judge the influence of the steady-state propeller loading will be to gather the calculation results for the classic propeller curve, formula (1) or (3) evaluated separately and the ones taking into account friction influence, formulas (4) and (8), both for the cylinder pressure based and crank torque based excitations. This makes the total of four calculation cases to be prepared, evaluated and compared. The classic propeller curve results will be 
denoted by the propeller load factor of 1,00 whereas the ones that take friction into account will be denoted with propeller load factor of 0,96 .

Figure 3 presents the two described propeller steady-state loading curves expressed in terms of torque. Their difference appears to be small, especially around the shaft speed at MCR. However, the influence of this small difference to the maximal amplitude of tangential stresses due to torsional vibrations is not that small, as it will be showed further on.

The referent values to compare the calculation results may be obtained by the well-known torsional vibrations calculations program GTorsi ${ }^{6}$, produced and licensed by MAN Energy Solutions, Copenhagen.

Free vibration results may be properly compared on the basis of the lowest three natural frequencies of the propulsion shafting system model. Due to the very nature of the process of evaluation of these natural frequencies in the SimulationX, these results will also slightly vary from one of the mentioned calculated cases to another one.

Forced vibration results will be properly compared if their comparison is based upon the maximal amplitude of the torsional tangential stress in the intermediate shaft and the propeller shaft. All of them are to be taken at the relevant critical speed, which also has to be stated out in the comparison tables.

The only calculation case results to be presented are the ones based upon normal firing in each and every cylinder of the engine.

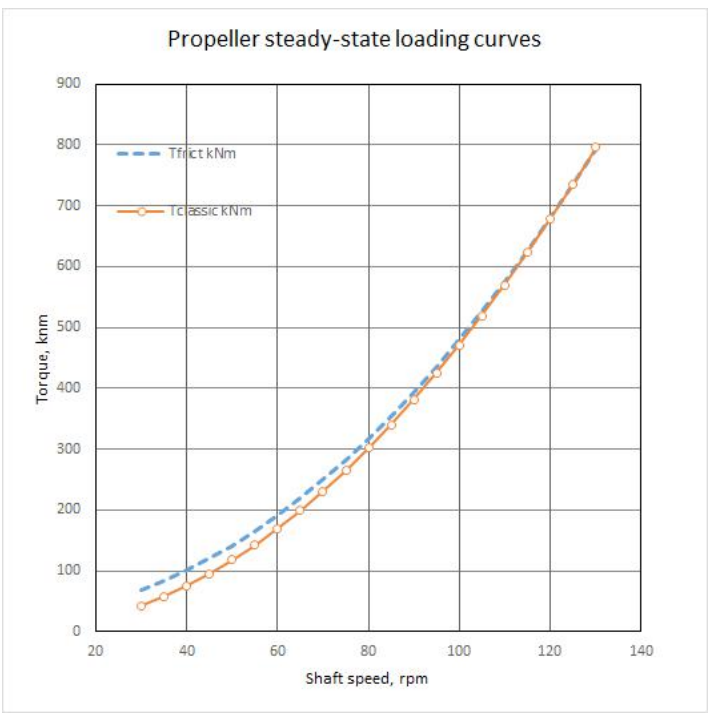

Figure 3. Propeller steady-state loading curves for classic and frictional approach 
Tables 1 and 2 present the results obtained for the free torsional vibrations, whereas tables 3 and 4 show the results for the forced vibrations. The reference values in tables 3 and 4 are the ones obtained by means of the software GTorsi, based upon analytical approach.

Table 1. Results of calculations for the free torsional vibrations, absolute values

\begin{tabular}{|l|c|c|c|c|}
\hline $\begin{array}{l}\text { Excitation in engine } \\
\text { cylinders }\end{array}$ & $\begin{array}{c}\text { Propeller law } \\
\text { load factor }\end{array}$ & $\begin{array}{c}\text { Natural freq. } \\
\mathbf{n}_{1}, \mathbf{r p m}\end{array}$ & $\begin{array}{c}\text { Natural freq. } \\
\mathbf{n}_{\mathbf{2}}, \mathbf{r p m}\end{array}$ & $\begin{array}{c}\text { Natural freq. } \\
\mathbf{n}_{\mathbf{3}}, \mathbf{r p m}\end{array}$ \\
\hline GTorsi & - & 384,7 & 1629,6 & 3235,0 \\
\hline $\begin{array}{l}\text { Simul.X } \\
\text { cyl. press. }\end{array}$ & 1,00 & 383,2 & 1627,0 & 3215,7 \\
\hline $\begin{array}{l}\text { Simul.X } \\
\text { crnk. torq. }\end{array}$ & 1,00 & 383,5 & 1629,8 & 3216,1 \\
\hline Simul.X cyl. press. & 0,96 & 383,2 & 1627,0 & 3215,7 \\
\hline $\begin{array}{l}\text { Simul.X } \\
\text { crnk. torq. }\end{array}$ & 0,96 & 383,5 & 1629,8 & 3216,7 \\
\hline
\end{tabular}

Table 2. Results of calculations for the free torsional vibrations, relative differences

\begin{tabular}{|l|c|c|c|c|}
\hline $\begin{array}{l}\text { Excitation in engine } \\
\text { cylinders }\end{array}$ & $\begin{array}{c}\text { Propeller law } \\
\text { load factor }\end{array}$ & $\begin{array}{c}\text { Natural freq. } \\
\text { diff. } \\
\mathbf{\Delta} \mathbf{n}_{1}, \%\end{array}$ & $\begin{array}{c}\text { Natural freq. } \\
\text { diff. } \\
\mathbf{\Delta} \mathbf{n}_{2}, \%\end{array}$ & $\begin{array}{c}\text { Natural freq. } \\
\text { diff. } \\
\mathbf{\Delta} \mathbf{n}_{3}, \%\end{array}$ \\
\hline GTorsi & - & $0 \%$ & $0 \%$ & $0 \%$ \\
\hline $\begin{array}{l}\text { Simul.X } \\
\text { cyl. press. }\end{array}$ & 1,00 & $-0,4 \%$ & $-0,2 \%$ & $-0,6 \%$ \\
\hline $\begin{array}{l}\text { Simul.X } \\
\text { crnk. torq. }\end{array}$ & 1,00 & $-0,3 \%$ & $0,0 \%$ & $-0,6 \%$ \\
\hline Simul.X cyl. press. & 0,96 & $-0,4 \%$ & $-0,2 \%$ & $-0,6 \%$ \\
\hline $\begin{array}{l}\text { Simul.X } \\
\text { crnk. torq. }\end{array}$ & 0,96 & $-0,3 \%$ & $0,0 \%$ & $-0,6 \%$ \\
\hline
\end{tabular}

These differences as presented in terms of the percentage change of the values as presented in table 2 show a very small percentage difference of the calculated natural frequencies, regardless of whether they have been calculated by the classic program such as GTorsi, or the simulation modelling software, such as SimulationX. However, it is important to notice that there are differences in the natural frequencies calculated by the SimulationX cylinder pressure and crank torque cylinder excitation models. These differences are probably to be attributed to the very process of calculations upon which the simulation modelling has been based. Though in the physics of the actual mechanical system there is no justification for these differences to exist, they have actually been found here. So, 
the most important fact is that these differences are really small and they may be neglected in any of the presented calculation cases.

Table 3. Results of calculations for the forced torsional vibrations, absolute values

\begin{tabular}{|l|c|c|c|c|}
\hline $\begin{array}{l}\text { Excitation in engine } \\
\text { cylinders }\end{array}$ & $\begin{array}{c}\text { Propeller law } \\
\text { load factor }\end{array}$ & $\begin{array}{c}\text { Critical } \\
\mathbf{s p e e d} \\
\mathbf{n}, \mathbf{r p m}\end{array}$ & $\begin{array}{c}\text { Stress in } \\
\mathbf{i n t m} \mathbf{~ s h . ~} \\
\mathbf{T}_{\mathbf{a}}, \mathbf{N} / \mathbf{m m}^{\mathbf{2}}\end{array}$ & $\begin{array}{c}\text { Stress in } \\
\mathbf{p r o p . ~} \mathbf{s h} . \\
\mathbf{T}_{\mathbf{a}}, \mathbf{N} / \mathbf{m m}^{\mathbf{2}}\end{array}$ \\
\hline GTorsi & - & 64,1 & 95,3 & 70,0 \\
\hline $\begin{array}{l}\text { Simul.X } \\
\text { cyl. press. }\end{array}$ & 1,00 & 63,8 & 87,5 & 64,3 \\
\hline $\begin{array}{l}\text { Simul.X } \\
\text { crnk. torq. }\end{array}$ & 1,00 & 64,2 & 89,8 & 66,0 \\
\hline Simul.X cyl. press. & 0,96 & 63,7 & 95,0 & 69,8 \\
\hline $\begin{array}{l}\text { Simul.X } \\
\text { crnk. torq. }\end{array}$ & 0,96 & 64,2 & 94,8 & 69,6 \\
\hline
\end{tabular}

However, the situation is different with respect to the comparison of the forced torsional vibrations calculation results in terms of maximal torsional stress amplitudes, as presented in table 4.

The percentage changes as shown in table 4 again take the torsional stress amplitudes calculated by GTorsi as the reference. SimulationX model based upon cylinder pressure excitations (the $5^{\text {th }}$ row in tables 3 and 4) gives practically the same maximal torsional stress amplitudes at critical speeds in the intermediate shaft and the propeller shaft as GTorsi, so that its results could have been equally taken as the reference.

Table 4. Results of calculations for the forced torsional vibrations, relative values

\begin{tabular}{|l|c|c|c|c|}
\hline $\begin{array}{l}\text { Excitation in engine } \\
\text { cylinders }\end{array}$ & $\begin{array}{c}\text { Propeller law } \\
\text { load factor }\end{array}$ & $\begin{array}{c}\text { Critical } \\
\text { speed diff. \% }\end{array}$ & $\begin{array}{c}\text { Stress in } \\
\text { intm. sh. } \\
\text { diff. \% }\end{array}$ & $\begin{array}{c}\text { Stress in } \\
\text { prop. sh. } \\
\text { diff. \% }\end{array}$ \\
\hline GTorsi & - & $0 \%$ & $0 \%$ & $0 \%$ \\
\hline $\begin{array}{l}\text { Simul.X } \\
\text { cyl. press. }\end{array}$ & 1,00 & $-0,5 \%$ & $-8,2 \%$ & $-8,2 \%$ \\
\hline $\begin{array}{l}\text { Simul.X } \\
\text { crnk. torq. }\end{array}$ & 1,00 & $0,1 \%$ & $-5,7 \%$ & $-5,7 \%$ \\
\hline Simul.X cyl. press. & 0,96 & $-0,6 \%$ & $-0,4 \%$ & $-0,4 \%$ \\
\hline $\begin{array}{l}\text { Simul.X } \\
\text { crnk. torq. }\end{array}$ & 0,96 & $0,1 \%$ & $-0,6 \%$ & $-0,5 \%$ \\
\hline
\end{tabular}


However, it is obvious from the table 4 that these relative differences of $-8,2 \%$ or $-5,7 \%$, or in absolute terms $(87,5$ or $89,8 \mathrm{MPa}$ vs. $95,0 \mathrm{MPa}$ for intermediate shaft stress, as well as 64,3 or $66,0 \mathrm{MPa}$ vs. $69,8 \mathrm{MPa}$ for the propeller shafts) are not to be neglected. Dependent upon the allowable torsional vibration stresses as determined in ${ }^{2}$, it might even happen that these about $5 \mathrm{MPa}$ of difference would be decisive to prescribe barred speed range or not, dependent upon the shaft material tensile strength as taken into account in the calculation of the allowable stress.

Validation of the calculated results by the measurements on board has actually been performed, as is always the case for the first new building in series, in accordance with the IACS classification societies' rules. These results (Kramar et al. 2001) are available to the authors and they confirm that the calculations have been correctly performed. However, their presentation and discussion would be out of the scope of this paper and has been left out.

\section{Conclusions}

Torsional vibrations calculations are required by classification societies for the main propulsion shafting systems of newly built ships, or when these systems undergo significant conversions which may affect their vibrational behavior and response. These calculations and their results depend upon many influence factors. They may be performed by means of classic programs based upon analytical solutions of the vibrational problems, when they are available, as well as upon the simulation modelling programs based upon software packages such as SimulationX.

One of these influence factors is the steady-state propeller loading curve, expressed either in terms of torque vs. shaft speed (quadratic curve) or power vs. shaft speed (cubic curve), both well-known as the classic propeller curves.

Taking into account the influence of e.g. frictional forces on the components of the engine such as engine cylinders, mentioned steady-state propeller loading curve will be slightly changed and will depend upon the mechanical efficiency ratio. It is the basic aim of this paper to formulate both types of propeller curves and to explore the influence of this change of the propeller curve to the final outcome of the torsional vibrations calculations results, presenting it in the case study of the real newly built vessel.

The results as presented in the paper show that, though this influence may be expectedly neglected in the results of free vibrations calculations, this is not the case with the calculations of forced torsional vibrations. In this latter case, the difference in terms of maximal torsional stress amplitudes in shafts is not that high, but it cannot be neglected, because it may be decisive upon the prescription of barred speed range or not.

These results finally justify the use of the slightly more complicated propeller steady-state loading curve that takes into account the frictional losses in engine cylinders, rather than the classical simple propeller curve. 


\section{Acknowledgments}

Part of the research for this paper has been performed using the software obtained within the scope of the scientific research project named: "Functional integration of the University of Split, PMF-ST, PFST and KTF-ST through development of scientific and research infrastructure in the building of the Three faculties", contract number KK.01.1.1.02.00182.2.

\section{NOTES}

1. IACS Procedures - Volume 1:IACS General Procedures, Rev 15, International Association of Classification Societies (London, 2020)

2. Unified Requirement UR M68 Dimensions of propulsion shafts and their permissible torsional vibration stresses, Rev 2, International Association of Classification Societies (London, 2015)

3. VDI 2039, Torsional vibration of drivelines - Calculation, measurement, reduction. Düsseldorf, 43 - 44.

4. Basic principles of ship propulsion - Optimisation of hull, propeller and engine interactions for maximum efficiency, (publication 5510-0004-04), MAN Energy Solutions. Copenhagen, 2018, pp. 29-45.

5. MAN B\&W Diesel A/S introductory presentation, Symposium of Engine Dynamics. Pusan, May 1998.

6. GTorsi - Version 3.4.4 EXT, Torsional vibrations calculation program, User's Manual, MAN Energy Solutions. Copenhagen, 2018.

\section{REFERENCES}

Carlton, J., 2019. Marine Propellers and Propulsion. $4^{\text {th }}$ ed. Burlington, $473-480$.

Kramar, M. et al., 2001. Shafting Torsional Vibrations Test No. A100LF01-02-093, Reg. No. 9-2-388. Zagreb: Croatian Shipbuilding Institute.

Senjanović, I. et al., 2019. Analytical procedures for torsional vibration analysis of ship powertransmission system. Engineering Structures 178, $227-244$.

Senjanović, I. et al., 2019. Validation of analytical methods for the estimation of the torsional vibrations of ship power transmission systems. Ocean Engineering 184, $107-120$.

Vulić, N. et al., 2016. Damping and excitation in the torsional vibrations calculation of ship propulsion systems. In: CIET 2016 Proceedings, 245 - 246. Split: Croatia.

Vulić, N. et al., 2017. Selection and evaluation of marine shafting torsional vibrations calculation software. IMSC 2017 Proceedings, 221 - 229. Solin: Croatia. 
Vulić, N. et al., 2007. Verification of Crankshaft Design and Fatigue Strength for in-line and v-type Marine Diesel Engines. Strojarstvo 49(4), 317-331.

$\triangle$ Nenad Vulić

Web of Science Researcher ID: D-7523-2017

Karlo Bratić

Web of Science Researcher ID: A-9211-2019

Branko Lalić

Web of Science Researcher ID: H-2258-2017

Ladislav Stazić

ORCID iD: 0000-0002-9921-3895

Faculty of Maritime Studies

University of Split

Split, Croatia

E-mail: nvulic@pfst.hr

E-mail: kbratic@pfst.hr

E-mail: blalic@pfst.hr

E-mail: 1stazic@pfst.hr 